\title{
OVERVIEW OF THE ROAD NETWORK MANAGEMENT SYSTEM
}

The long-term high standard research in civil engineering at the Department of Construction Management contributed to the fact that Slovakia succeeded to create its own pavement management system called Road Network Management System, which was accepted by international financial institutions on providing investment credits for rehabilitation of road network. At present, when the system has been in operation for more than 15 years, we can assess and analyse the results achieved in practice. This article presents a concise overview of the Road Network Management System. Computational details of pavement distress assessment and pavement structure evaluation are omitted, the focus lays on the decision making procedures for selection of appropriate repair action and process or priorization and optimization.

Keywords: Road Network Management System, Pavement Management System, Decision making, Prioritization, Optimization.

\section{Introduction}

The Road Network Management System (RNMS) emerged in the early ' 90 s when the first structure of the system including individual modules was established based on the integrated Pavement Management Systems [1]. These modules were created to describe elements, processes and the creation of regulations in areas of Pavement Evaluation, Repair Method Selection, Life Cycle Cost Analysis (LCCA), and Funding Allocation. The outputs of RNMS development are the different sophistication levels of operational funding allocation, with the main aim to maintain the road network at the required technical and operational level. At various stages, optimization of the funding allocation process was achieved through the implementation of probabilistic methods and exact methods. The system started as a probabilistic empiricintuitive decision making tool (a.k.a. Expert System) in which technical considerations and expert estimates were the decisive factor, concurrently with the application of Markov chain model. The system performed well and it produced valid Maintenance Repair \& Rehabilitation (MR\&R) action schedules. However, the Expert System was very influenceable by subjective judgement of evaluators in charge. Therefore, further development in this direction was abandoned and efforts commenced to rework the system to operate on the basis of exact methods [2].

\section{Road Inventory and Pavement Distress Assessment \& Pavement Structure Evaluation}

Main part of this module is a database aggregating data regarding the road network. In addition to data on traffic volume and physical characteristics of road sections, as well as physical characteristics of other road network assets such as bridges and culverts, substantial part of the database consists of data regarding surface characteristics of pavements, i.e. pavement distress data. The RNMS differentiates among these types of pavement distresses: Roughness, Rut depth, Skid resistance and Surface distress.

Within the RNMS, evaluation of pavement structure is used for the calculation of residual service life, overlay thickness and optimization of performed repairs [3]. These calculations are based on measurements of deflection bowl induced by the dynamic deflectometer FWD KUAB 150 [4]. The calculations are, for the needs of RNMS, incorporated into software called Comprehensive Analysis of the Pavement Bearing Capacity CANUV [4].

- Pavement Structure - Residual Service Life Calculation - uses the elastic modulus of asphalt layers,

- Overlay Thickness Design - is based on pavement design method; the method utilizes the characteristics of surfacing, sub-base and subgrade of particular pavement.

\footnotetext{
* Jan Mikolaj, Lubos Remek, Lubomir Pepucha

Department of Construction Management, Faculty of Civil Engineering, University of Zilina, Slovakia

E-mail: jan.mikolaj@fstav.uniza.sk
} 


\section{MR\&R Method Selection}

This module is necessary due to the fact that various MR\&R actions can be performed using several methods. The decision whether it is sufficient or insufficient to apply surface dressing, microsurfacing thin overlay, thick $40-80 \mathrm{~mm}$ overlay, or undertake complete reconstruction which would include subgrade or sub-base rejuvenation, depends primarily on evaluation of pavement structure. The MR\&R methods are arranged into algorithm through which appropriate method can be selected, this selection algorithm is shown in Fig. 1.
The decision making algorithm itself is based on the outputs of pavement evaluation and evaluation of pavement structure, i.e. outputs of the first two RNMS modules, and consecutively, the calculation of required overlay thickness. Depending on Pavement Condition - the level of surface damage and rutting depth - it may not be necessary to reinforce the pavement; instead, a thin overlay technology can be selected for rejuvenation of pavement surface including a milling and replacement of upper part of the surfacing layer. Thickness of the overlay is chosen according to calculated reinforcement thickness provided that reinforcement of the

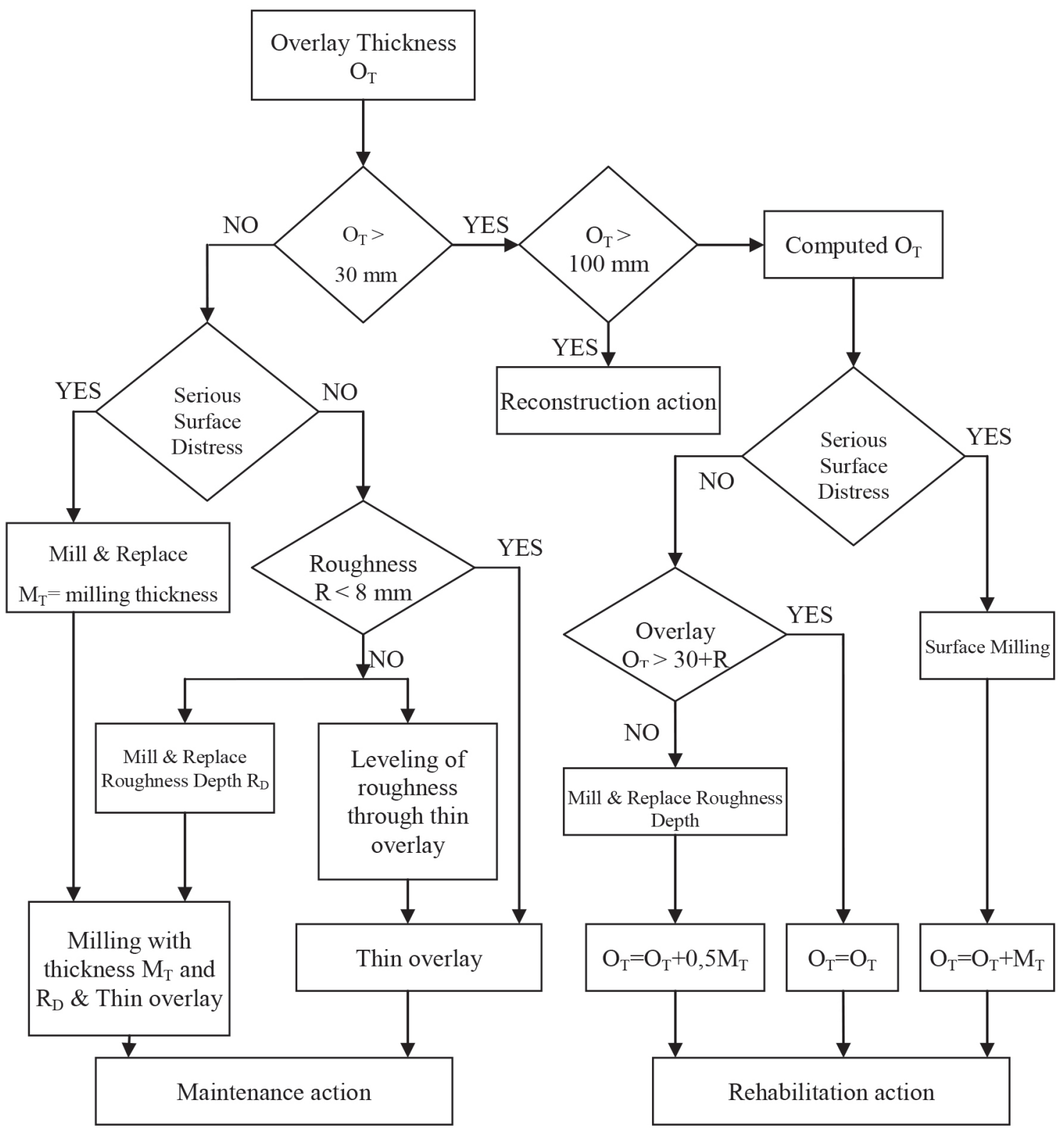

Fig. 1 Repair method selection algorithm 
pavement is necessary. A detailed rehabilitation project has to be prepared in case that reconstruction of the pavement is necessary.

The MR\&R methods, be it dressings, thin overlays, mill and replace, recycling or overlays are chosen by individual road administrators themselves. Their decision is based on their Library of Technologies, created according to their individual technological resources or according to resources of their public sector subcontractors.

\section{RNMS as a Decision Making Tool}

In terms of decision-making procedures, RNMS uses the prioritization and optimization approach. For the RNMS, a number of separate modules were established. These submodules consist of database containing road network parameters, algorithms for pavement distress and pavement structure evaluation, algorithm for selection of appropriate MR\&R method and methodology for Life-Cycle Cost Analysis. In terms of pavement analysis, in addition to pavement serviceability, the emphasis lies on evaluation of pavement structure.

The RNMS operates at:

- Road Network Level - prioritization and optimization of MR\&R actions and optimization of MR\&R strategies.

- Project Level - optimization of Rehabilitation and Reconstruction (R\&R) actions and assessment of new infrastructure investments.

At network level, in contrast to the well-established standards, RNMS includes much more detailed data regarding pavement structure evaluation such as residual service life and overlay thickness which are the base for decision whether maintenance, rehabilitation or reconstruction actions is appropriate. This decision, if done properly, will allow for considerably more realistic MR\&R policies, programming, and schedules.

Operations on project level are based mainly on the diagnostics and evaluation of the pavement structure. Data from the trailer mounted dynamic impulse loading device KUAB FWD - falling weight defelectometer - are supplemented by measurements of complex modulus of elasticity on samples extracted from asphalt layers of the analyzed pavement section. Subsequently, local influences are assessed in relation to the repair technologies and their durability, as well as regional pricing specifications, e.g., market prices charged by contractors of the repair actions. The output is an exactly defined list of appropriate MR\&R actions, according to this schedule, road network administrators can prepare contract for suppliers of MR\&R works.

The main decision making criterion is economic efficiency, which enables us to create incisive outputs like strategy for allocation of limited funds between particular road sections, or the total funding amount necessary for preserving the road network in serviceable condition. In principle, economic efficiency assessment evaluates the impact of all MR\&R actions.
The positive effect - improvement of current state - of these actions has to overweigh their construction costs. Identification and calculation of benefits generated through repaired pavements is a key factor for economic efficiency calculation. Road user benefits are calculated as savings, i.e., difference between higher road user costs prior to the MR\&R action and road user costs after the MR\&R action. Each MR\&R method has its expected serviceability defined by its pavement performance functions equation (1).

$R U B=\sum_{t=1}^{z}\left[\left(R U C_{D S}-R U C_{D N}\right) \cdot k_{D E G} \cdot k_{A T G}\right]$

$k_{D E G}=1-\left(\frac{t}{z}\right)^{B}$

where:

RUB = road user benefits,

$\mathrm{RUC}_{\mathrm{DS}}=$ road user costs in "do something" variant,

$\mathrm{RUC}_{\mathrm{DN}}=$ road user costs in "do nothing" variant,

$\mathrm{k}_{\mathrm{DEG}}=$ coefficient of function predicting condition of the pavement,

$\mathrm{k}_{\text {ATG }}=$ annual transportation growth coefficient,

$=$ years $1-\mathrm{z}$,

= service life of MR\&R action,

$=$ pavement structure parameter.

The coefficient of degradation $\mathrm{k}_{\mathrm{DEG}}$ calculated according to equation (2) is a mathematical expression for degradation of surface characteristics. This coefficient is a parameter of a fundamental importance for the accuracy and validity of economic efficiency calculation. For the needs of the RNMS, the trend lines for degradation of skid resistance, longitudinal and transverse roughness and surface distress were derived according to outputs of Circular Test Track which is an outdoor accelerated pavement testing facility - Fig. 2.

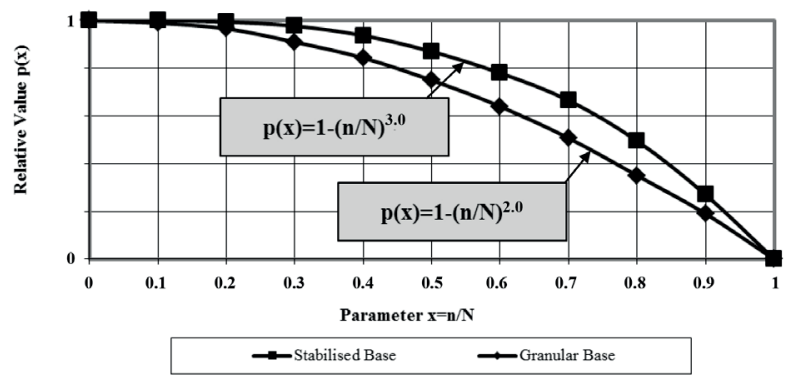

Fig. 2 Degradation functions of IRI for flexible pavements $B=2.0$ and semi-rigid pavements $B=3.0$ [5] 


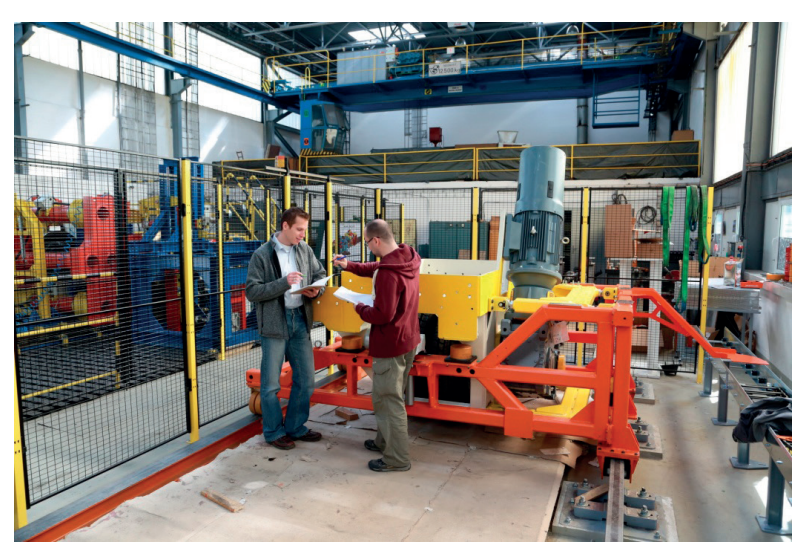

Fig. 3 Experimental pavement testing facility

Currently, the CCT is not in service anymore, mainly due to energy costs of its operation. At present, the trend lines of degradation are being verified using results of measurements carried out for the needs of Slovak Road Inventory (Research Institute of Engineering Constructions, 1993). However, given the large number of input variables and conditions, and thus the large dispersion of the results, construction of a new experimental test facility started at the University of Zilina. This facility will simulate traffic load, and subsequently, scrutinize inducted pavement response on a 1:1 model - Fig. 3 .

\subsection{Prioritization}

Prioritization program is a necessity, as it is required by road administrators; road administrators are obliged to deal with insufficient funding, they are also responsible for maintaining the road network in satisfactory condition. Therefore, priorities have been established; these priorities include: functional categorization of road communications, blackspots, extreme traffic volume, extent, severity of pavement distresses and cost effectiveness.

RNMS provides a full set of outputs for network and project level assessment. In particular, the prioritization of fund expenditures allocated for MR\&R policies and creation of site specific plans for $M R \& R$ actions, i.e., plans for meeting the performance objective. For network level assessment, the final output is a cumulative table which includes a final list of selected road sections and corresponding repair types - Table 1 . The table shows all necessary data required for final decision. In addition, several other outputs are generated, for instance, pavement distress data and traffic related data, data regarding the results of the evaluation - IPSV, IRI, selected MR\&R technology, their costs, traffic load and internal rate of return. Price for the repair is only an estimated value; the real value will be based on competition process where contractor for the construction works will be selected.

\subsection{Optimization}

Optimization program, in addition to establishment of general options for optimal treatment for each possible combination of performance variables, deals with optimization of timing of $\mathrm{R} \& \mathrm{R}$ actions. The program is based on a mathematical model for calculation of optimal repair time. This model consists of cost optimization, namely, calculation of construction costs and subsequent sum of annual maintenance costs for the duration of residual service life. However, the requirement of this calculation is the application of an analytical calculation of the residual service life and calculation of the overlay thickness in each year of the residual service life. Subsequently, user costs are calculated for each $R \& R$ variant and each year of its possible implementation. The optimal variant and year is the one with the lowest sum of construction, maintenance and user costs [1].

The calculation consists of two procedures. Firstly, calculation of pavement performance trend line. Secondly, subsequent calculation of overlay thickness for each year, until the end of pavement's residual life. The overlay thickness of the structure is related to point in time at which the action will take place - it grows over time. Overlay extends service life of the pavement and reduces user costs. Optimal time is calculated as the sum of construction costs for the reinforcement, user costs before reinforcement and user costs after the action. This sum of costs is divided by the number of years of newly extended

Example of road works prioritization- MR\&R action plan

Table 1

\begin{tabular}{|c|c|c|c|c|c|c|c|c|c|c|c|c|c|}
\hline No. & Road & Road Section & $\begin{array}{c}\text { Lenght } \\
{[\mathrm{m}]}\end{array}$ & Price $[€]$ & $\begin{array}{c}\text { Cumm. } \\
\text { price } \\
{[€]}\end{array}$ & $\begin{array}{c}\text { IRI } \\
{[\mathrm{m} / \mathrm{km}]}\end{array}$ & $\begin{array}{c}\text { Kpo } \\
{[\mathrm{mm}]}\end{array}$ & $\begin{array}{c}\text { Pavement } \\
\text { operating } \\
\text { condition } \\
\text { index }\end{array}$ & $\begin{array}{c}\text { Repair } \\
\text { Works }\end{array}$ & IRR & AADT & $\begin{array}{c}\text { AADT } \\
\text { of } \\
\text { Trucks }\end{array}$ & $\begin{array}{c}\text { Price } \\
€ / 1 \mathrm{~km}\end{array}$ \\
\hline 1. & $\mathrm{I} / 50$ & $\begin{array}{c}\text { Rimavka } \\
\text { Sobota }\end{array}$ & 2746 & 296500 & 296500 & 5.14 & 19.44 & 1.21 & $0, \mathrm{z}$ & 77.6 & 6830 & 1299 & 107975 \\
\hline 2. & $\mathrm{I} / 61$ & Dubnica n. V. & 703 & 161428 & 457928 & 4.55 & 20.23 & 3.11 & 0 & 55.3 & 17093 & 1329 & 229628 \\
\hline 3. & $\mathrm{I} / 66$ & Cifer & 1000 & 154518 & 612446 & 4.59 & 10.12 & 1.95 & $\mathrm{z}$ & 49.7 & 11200 & 1495 & 154518 \\
\hline 4. & $\mathrm{I} / 50$ & Krivan & 1962 & 586600 & 1199046 & 5.77 & 21.84 & 0.11 & $\mathrm{z}$ & 49.4 & 9535 & 2349 & 298981 \\
\hline 5. & $\mathrm{I} / 18$ & Liskova & 3797 & 961359 & 2160405 & 3.67 & 16.68 & 1.05 & $\mathrm{z}$ & 48.7 & 14078 & 1857 & 253189 \\
\hline
\end{tabular}


service life. This is shown in equation (3). The model shows that the later we carry out the reinforcement, the more expensive the reinforcement will be in terms of construction and user costs. Reinforcement prior to the optimal time will produce little change to the user cost and small extension of service life. Even greater precision of this optimal life calculation is attained if we take into account the maintenance costs for variants with, and without the reinforcement.

$O I=\frac{\left(C C+U C_{B R}+U C_{A R}\right)}{T t}$

where

OI = optimization index;

$C C=$ construction costs;

$U C_{B R} \quad=$ sum of user cost before reinforcement;

$U C_{A R} \quad=$ sum of user cost after reinforcement;

$T t \quad=$ number of years of extended service life.

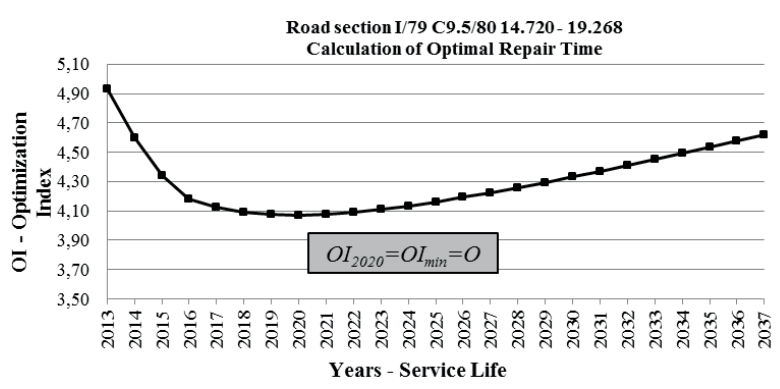

Fig. 4 Calculation of Optimal Repair Time for road section I/79 C9.5/80 $14.720-19.268$

Optimization index is computed for each year of the whole service life. As seen in graph shown in Fig. 4, the lowest point on the OI curve - OImin - represents the optimal time for the R\&R action. At this point in time, the $R \& R$ action will be preventive instead of reactive and will yield largest amount of benefits.

\section{Conclusion}

RNMS, despite its theoretical character, has been exhibiting practical application for nearly 18 years. The application of the system resulted in the fact that the resources are allocated to road sections which have the highest demand for repairs, thus financial funds are used effectively. The saved funds are in turn used as additional resources for more repairs. Also important is the fact that this systematic approach increased the discipline of subcontractors of repair works which are being employed by road administrators. All potential deficiencies are revealed by means of diagnostics. The road network administrator has, by means of the new system, a huge number of results which are enabling him to optimize his activities; for example, the trend lines of roughness, skid resistance or surface damage. On the 1st class road network - unlimited access trunk road network - average rutting depth was reduced as a result of the RNMS which diversifies between different causes of the rutting and recommends appropriate repair technology. The results of the RNMS application proved that it is possible to optimize resources by this sophisticated decision making process. Based on calculations of the residual service life and overlay thickness it is possible to select more economical MR\&R methods like dressings and thin overlays.

RNMS application has allowed us to spend resources more effectively, which was a requirement for other methods of financing, for instance financing through European Investment Bank loans or Public Private Partnerships.

\section{Acknowledgement}

The research is supported by the European Regional Development Fund and the Slovak state budget for the project "Research Centre of University of Zilina”, ITMS 26220220183.

\section{References}

[1] MIKOLAJ, J.: The Road Network Management System in Slovakia. Transport Reviews, vol. 16, No. 4, 1996, 313-321, Taylor and Francis Ltd.: London.

[1] MIKOLAJ, J.: Research report: N 05514907 E 03 IDU 3: Enhancement of Performance and Serviceability of Roads. Road Maintenance and Rehabilitation Planning System. University of Zilina, 1992, SCHLOSSER, F., SRAMEKOVA, E., SRAMEK, J.: Rheology, Deformational Properties and Fatigue of the Asphalt Mixtures, Advanced Materials Research, vol. 875-877, 2014.

[2] Engineering \& Research Int. Inc., 2013. KUAB Falling Weight Deflectometer [online]. Available from: http://www.erikuab.com/ kuab.htm [Accessed 10 April 2013].

[3] KOMACKA, J., CELKO, J.: CANUV - Computer Program for Analysis of the Bearing Capacity on the Deflection Bowl Basis. Communications - Scientific Letters of the University of Zilina, 19, 1996, 63-70.

[4] VUIS CESTY, s.r.o: Evaluation of Functional Serviceability of Pavements, Research task N 05-514-904, Report 1993, Bratislava 1993. 